\title{
Peripheral Vascular Injuries - Not to Miss or Mess Them!
}

\author{
Zia Ur Rehman \\ Department of Surgery, The Aga Khan University Hospital, Karachi, Pakistan
}

Trauma is one of the leading causes of death and disability in young-to-middle age group. Most of the deaths are due to catastrophic bleeding. Controlling bleeding at appropriate time and restoring circulation can improve the outcome of many patients. There are a handful of vascular surgeons in Pakistan. Most of them are concentrating in the main cities. There are no vascular surgeons or services at district level. Many patients lose their limbs and lives due to non-availability of much needed interventions at appropriate time. There is little formal teaching about vascular diseases at the undergraduate and even at postgraduate levels; and most surgical training programmes lack dedicated vascular surgery rotation.

Peripheral vascular injuries are challenging to manage. Majority of the cases are due to gunshots and road traffic accidents. The incidence rises when law and order situation is not ideal within the country. Victims are usually young individuals who are productive members of society. It is a common observation that a patient with vascular injury going to multiple hospitals before reaching the appropriate setup and had wasted precious time when a fruitful intervention could have been performed. Usually, when the patient reaches to the appropriate facility, the limb is at the verge of amputation or patient is collapsing. A recent study looked into the factors for delayed presentation of the patients to vascular surgeons in Pakistan, and found $72.72 \%$ of the patients with acute limb ischemia presented with a delay greater than 12 hours. More than half of those were having traumatic vascular injuries. Common reasons for delayed presentations were non-referral by the primary physicians, patient's unawareness, and lack of access to vascular surgeon. 1

A thorough physical examination is important in the management of these injured patients as peripheral vascular injuries can be distracting. One has to be focused in these poly-trauma patients as not to miss lifethreatening injuries. There is always risk of missing a major abdominal or chest injury by the very site of a mangled extremity.

Correspondence to: Dr. Zia Ur Rehman, Section of Vascular Surgery, Department of Surgery, The Aga Khan University

Hospital, Stadium Road, Karachi, Pakistan

E-mail:ziaur.rehman@aku.edu

Received: March 21, 2019; Revised: May 07, 2019;

Accepted: May 20, 2019
Haemorrhage control by manual pressure or by tourniquet application, and shifting the patient rapidly to a centre where definitive care can be provided are the most important steps in the management of these patients. ${ }^{2}$ In the pre-hospital setting, immediate application of the tourniquet may be justified for life threatening haemorrhage, which is not controlled by simple methods. ${ }^{3}$ A prospective study showed that early tourniquet use, before the onset of shock, was associated with a $90 \%$ survival rate versus $10 \%$ survival, if application was delayed until the casuality was in shock. ${ }^{4}$

Delay in diagnosis results in irreversible ischemic changes, impaired limb function or even limb loss. ${ }^{5}$ Most important diagnostic tool in extremity arterial trauma is the physical examination, specifically searching for the presence or absence of hard and/or soft signs. ${ }^{6}$ Patients with hard signs need immediate exploration, if the mechanism of injury is penetrating and the location of the injury is apparent without further investigations. Unnecessary investigations to confirm these injuries can waste precious time as "minutes are muscles". Two hours of limb ischemia can cause permanent nerve damage and 4-6 hours of limb ischemia causes muscle death. After that time, even if the limb is revascularised, it will be functionless. Skin changes points to delayed presentation and prolong limb ischemia. It needs high degree of suspicion to detect these injuries in 'golden time period' when the limb can be revascularised. Most of patients with soft signs can be managed conservatively. Ankle brachial pressure index (ABPI) can be a useful bed-side test to detect occult injuries. Value less than 0.9 seems to be highly sensitive $(95 \%-100 \%)$ and specific (97\%-100\%) for arterial injury compared to arteriography. ${ }^{7}$ Emergency physicians and surgeons can learn its proper technique and limitations; and can avoid unnecessary investigations and admissions.

Non-vascular surgeons have little exposure of dealing vascular emergencies. Imparting knowledge and skills of managing peripheral vascular injuries to non-vascular surgeons can fill the expertise gap. Teaching them basic skills of vessel handling, getting proximal and distal vessel control, performing embolectomy and fasciotomy can help a lot of patients. This can be done by focused courses.

Making a 'decision' of primary amputation versus limb revascularisation is difficult in a patient with peripheral vascular injuries. ${ }^{8}$ Life takes precedence over the limb. 
The goal of vascular reconstruction is to get a functional limb; as a functionless limb is worse than prosthesis. Patients need to be well hydrated to protect from reperfusion injury. These principles are simple but often missed.

There are meagre expertise and resources available which need to be utilised in an organised and effective manner. Designating a dedicated centre in every major city and then directing all vascular emergencies can sort the issue of communication and referral.

It is time to increase awareness among doctors who manage these injured patients, and especially the surgeons who manage these cases, by improving their generic skills. This will definitively save a lot of lives and limbs. We suggest awareness workshops to improve knowledge and skills of first responders, particularly surgeons dealing these emergencies.

\section{REFERENCES}

1. Khan AR, Shaikh FA, Riaz A, Rehman ZU, Sophie Z, Siddique NA. Why do patients with limb ischemia present late to a vascular surgeon? A prospective cohort study from a developing world. J Pak Med Assoc 2019; 69:S3-S6.
2. Woodward EB, Clouse WD, Eliason JL, Peck MA, Bowser AN, Cox MW. Penetrating femoropopliteal injury during modern warfare: Experience of the Balad Vascular Registry. $J$ Vasc Surg 2008; 47:1259-64.

3. Pikoulis E, Salem KM, Avgerinos ED, Pikoulis A, Angolou A, Pikoulis A, et al. Damage control for vascular trauma from the prehospital to the operating room setting. Front Surg 2017; 4:73.

4. Krag JF, Littrel ML, Jones JA, Walters TJ, Wader CE. Battle casualty survival with emergency tourniquet use to stop limb threatening bleeding. J Emerg Med 2001; 41:590-7.

5. Vielgut I, Gregori I, Holzer LA, Glehr M, Hashemi S, Platzer P. Limb salvage and functional outcomes among patients with traumatic popliteal artery injury: A review of 64 cases. Wien Klin Wochenschr 2015; 127:13-4.

6. Evans C, Chaplin T, Zelt D. Management of major vascular injuries: Neck, extremities, and other things that bleed. Emerg Med Clin North Am 2018; 36:181-202.

7. Lynch K, Johansen K. Can Doppler pressure measurement replace "exclusion" arteriography in the diagnosis of occult extremity arterial trauma? Ann Surg 1991; 214:737-41.

8. Williams ZF, Bools LM, Adams A, Clancy TV, Hope WW. Early versus delayed amputation in the setting of severe lower extremity trauma. Am Surg 2015; 81:564-8. 